\title{
Sex differences in visuospatial working memory: Components of cognitive processing
}

\author{
SUSAN LORING-MEIER \\ Loma Linda University, Loma Linda, California \\ and \\ DIANE F. HALPERN \\ California State University, San Bernardino, California
}

\begin{abstract}
Numerous studies have shown that sex differences in visuospatial tasks vary in size and direction depending on the nature of the task, with large differences favoring males on tasks that require transformations in visuospatial working memory. The cognitive processes underlying these differences were investigated using laboratory tasks developed by Dror and Kosslyn (1994). Four cognitive components of visuospatial working memory were assessed-image generation, maintenance, scanning, and transformation-in an attempt to identify the components that would show differential effects for females and males. The image generation task required retrieval of shape information from long-term memory, generation of a visual image in working memory, and utilization of the information about the shape in a decision task. The image maintenance task required only the latter two processes. The information processing demands required by scanning and rotation tasks came from the need to transform the visual image so that it could be used in decision making. Males responded more quickly on all four tasks ( $d s$ between .63 and .77 ), with no between-sex differences in accuracy. We concluded that speed of processing is central to understanding sex differences in visuospatial working memory. We discuss implications of these findings for performance on real-world visuospatial tasks.
\end{abstract}

The ability to maintain a representation of spatial information while simultaneously imagining what objects would look like if they were moved in space, viewed from another perspective, or had their shape altered is critically important for architects, dentists, chemists, pilots, carpenters, clothing designers, and others who work in similar fields. Despite the fact that skillful performance on visuospatial tasks is essential in a wide variety of applied settings, surprisingly little is known about the cognitive components that are utilized in accomplishing these tasks.

A large body of research over the last 25 years has shown consistent sex differences ${ }^{1}$ in some, but not all, tasks that rely on visuospatial working memory (Halpern, in press; Halpern \& Crothers, 1997; Linn \& Petersen, 1985). Males, for example, consistently outperform females on tasks that require transformations in visuospatial working memory, such as the ability to mentally rotate a stationary

This study was conducted by the first author in partial fulfillment of the requirements for the Master of Arts degree in psychology at California State University, San Bernardino. The authors thank Itiel Dror for graciously sharing the stimuli he developed, David Riefer and Hideya Koshino at California State University, San Bernardino, for valuable advice on data analysis and comments on an earlier draft of this article, and Daniel Voyer at St. Francis Xavier University and Dr. Veronica Dark at lowa State University for helpful comments and advice. Correspondence should be addressed to D. F. Halpern, Department of Psychology, California State University, 5500 University Parkway, San Bernardino, CA (e-mail: dhalpern@csusb.edu). figure or imagine the folded or unfolded appearance of an object. Male-female differences on mental rotation tests, which require subjects to make comparisons between two figures that differ in orientation, yield large effect sizes ( $d=.90$, Masters \& Sanders, 1993; $d=.94$, Voyer, Voyer, $\&$ Bryden, 1995) that have remained unchanged over the last two decades. These tasks place a particularly high demand on visuospatial working memory because they require at least two visuospatial component processes working in concert: the maintenance of a spatial image (a short-term memory or storage component) and its simultaneous transformation (a processing component).

Unlike cognitive tasks that rely primarily on transformations of visuospatial stimuli, tasks that require memory for location show a female advantage (Birenbaum, Kelly, \& Levi-Keren, 1994; Eals \& Silverman, 1994; Silverman $\&$ Eals, 1992). These results are supported by studies that have found that females also recall more landmarks when learning and using routes (Galea \& Kimura, 1993) and recall more objects in real-life locations (Hill et al., 1995). Recent research has suggested that the female advantage on these spatial tasks may be mediated by better object memory and not location memory per se (James \& Kimura, 1997).

Memory for location tasks primarily depends on retrieval from long-term memory, whereas the other tasks (e.g., mental rotation with the stimulus visually displayed or maintained in memory) place the heaviest processing demands on visuospatial working memory. The 
division into long-term memory and working memory components is not absolute since most tasks involve both memory systems to some degree. Many other memory tasks that depend on retrieval from long-term memory show, on average, a female advantage (Stumpf \& Jackson, 1994). For example, Herlitz, Nilsson, and Bäckman (1997) recently reported results from a large Swedish sample of adults (35-80 years of age) in which the females showed superior recall for episodic memory tasks, with no sex differences on semantic, working, or priming memory tasks. There are also reports of female superiority on intentional learning tasks (e.g., recall of word lists; Schaie \& Willis, 1993) and, in general, the recall of verbal information from long-term memory (e.g., synonym generation; Halpern \& Wright, 1996). It is clear that memory is not a univariate construct, and sex differences vary as a function of many variables, including the recall interval (working memory vs. long-term memory), nature of the material being recalled (verbal vs. visuospatial), and the intention of the subject (intentional vs. incidental), among others.

In addition to sex differences, age differences are also found on specific visuospatial tasks. In general, older adults do not perform as quickly or as accurately as younger adults on mental rotation tasks and other similar tasks that put high processing demands on visuospatial working memory (e.g., Clarkson-Smith \& Halpern, 1983; Hertzog, Vernon, \& Rypma, 1993). Age-related declines in visuospatial tasks are of both theoretical and applied interest, given that an increasing portion of the work force is still active well beyond age 65 , the age formerly considered as the traditional age for retirement. Consistent differences are also found among members of different professions. For example, pilots perform significantly better than nonpilots on several visuospatial tasks (Dror, Kosslyn, \& Waag, 1993). When older adults are compared with (matched) younger adults and when pilots are compared with nonpilots, the largest differences among all of the visuospatial tasks are found on mental rotation tasks-a result that parallels the usual findings when males and females are compared. It may be that the dual and simultaneous demands of maintaining and transforming an image have an additive effect so that any group differences in either of these processes are increased by the addition of the second. The conceptualization of visuospatial tasks as composed of component processes permits a more fine-grained analysis of what subjects actually are doing as they work on these tasks. We hypothesized that if visuospatial processing could be dissociated into separate components, then we should be able to identify the process or processes that underlie sex differences in these tasks, thereby, providing a key to understanding sex differences in tasks that rely on visuospatial working memory.

Dror and Kosslyn (1994) applied a component process approach to study aging effects on visuospatial tasks. They examined four aspects of images in visuospatial working memory: (1) generation, (2) maintenance, (3) scanning, and (4) transformation. Each of these tasks also varied in level of complexity based on the assumption that any group differences that emerged at lower levels of complexity would be increased as the task become more complex. They found that performance on image generation and transformation declined in older subjects as the task became more complex, with no age-related differences as a function of complexity in image maintenance and scanning. They concluded that the cognitive processes involved in visuospatial working memory age selectively.

Dror and Kosslyn's (1994) tests of visuospatial working memory provide a new way of conceptualizing the component processes involved in abstracting and using visuospatial information. We used their experimental paradigm to determine whether the four component processes they identified would show differential effects for males and females and thereby allow us to specify which components would be expected to show the largest betweensex differences. To our knowledge, there are no other studies that directly compared females and males on multiple components in visuospatial processing - the ability to generate a visuospatial image, maintain the information in that image, transform it in various ways, and then utilize it to perform a spatial-cognitive task.

In his influential theory of working memory, Baddeley $(1990,1992)$ proposed a tripartite model-one that is composed of an executive function that controls attention, a phonological loop that is essential for processing speech-based information, and a visuospatial sketch pad. Baddeley's model provided a useful framework for conceptualizing the cognitive processes that underlie the four imagery tasks used in the present study. The role of the phonological loop was not investigated because we focused on the processing of visuospatial information. The image generation task required retrieval of information about the shape of a letter from long-term memory into the visuospatial sketch pad, where it was used (by the central executive) in decision making. By contrast, the image maintenance task required short-term maintenance of an image in the visuospatial sketch pad and use (by the central executive) of the information in decision making, without support from long-term memory. Given that females usually show an advantage on tasks that require retrieval of information from long-term memory, especially verbal information, it was predicted that the image generation task would favor females; whereas, the image maintenance task, which did not involve access to longterm memory, would favor males. The scanning and rotation tasks primarily involve the mental manipulation of perceptually available information by the central executive in the visuospatial sketch pad. The scanning task was a simpler manipulation, which utilized fewer processing resources than the rotation task, and thus was expected to show smaller female-male differences.

Each of the tasks in the present study contained two or three levels of complexity. We predicted that sex differences would be largest and most consistent as complexity level increased, on the basis of the literature suggesting that sex differences become greater as a function of 
task complexity (Collins \& Kimura, 1997; Okagaki \& Frensch, 1994).

\section{GENERAL METHOD}

\section{Subjects}

Following Cohen and Cohen's (1983) power analysis guidelines for large effect sizes, it was determined that 24 females and 24 males were needed for power $=.80$. The subjects were 48 adults, (mean age for females $=29.14$ years, $S D=10.08$; mean age for males $=28.83$ years, $S D=8.21$ ), with ages ranging from 18 to 48 . All were volunteers from a university subject pool, recruited in accord with campus policies (i.e., class announcements and bulletin board postings). Extra class credit was awarded for their participation.

\section{Procedures}

Four visuospatial tasks were computer-administered in a DOS environment via the Micro Experimental Lab (MEL) program on a computer (Schneider, 1989). All trials began with the presentation of an exclamation point, which remained on the screen until the subject pressed the space bar. After a 500 -msec blank screen, the stimulus was presented. All responses were yes/no decisions made by pressing one of two keys with the index finger of their dominant hand. The "N" key was labeled "Y" for "yes," and the "M" key was labeled "N" for "no." The timing, nature of the stimulus, and nature of the decision varied across the four tasks. The tasks and stimuli developed by Dror and Kosslyn (1994) were used. The four sets of stimuli corresponded to four different visuospatial tasks: generating a visual image, maintaining an image, scanning an image, and rotating an image. Reaction times (RTs) and accuracy were recorded by the software program for each subject for each stimulus display. The subjects were asked to respond as quickly and as accurately as possible. Feedback was not given.

All tasks were administered using a sex $\times$ complexity, split-plot factorial design. Each task was composed of at least two levels of complexity. The subjects were tested individually, and the order of presentation of the four tasks was counterbalanced. The subjects read instructions for each task from the computer screen. Practice trials were presented before each task to allow the subjects to ask questions and become acquainted with the procedure.

Data were tabulated separately for females and males for each of the four imaging tasks. For each task, separate analyses of variance (ANOVAs) were conducted, a data-analytic procedure that allowed direct comparisons with studies by Dror and Kosslyn (1994) and Dror et al. (1993). Outliers were defined as RTs greater than 2 standard deviations above each subject's individual mean. Outliers were replaced with the mean of that subject's remaining scores for that cell (Clarkson-Smith \& Halpern, 1983).

\section{Task 1}

\section{Image Generation}

\section{Method}

The image generation task initially required the subjects to memorize the appearance of 10 uppercase block letters. Each letter appeared on the computer screen inside four brackets that formed a rectangular frame, with a lowercase script version of the same letter presented below the frame (see Figure 1 for example). Each letter remained visible for as much study time as needed by each subject and was repeated three times. Following this, the subjects were shown the script letters on flash cards, and they were asked to draw the corresponding block letter on a worksheet containing 10 sets of empty brackets, in order to facilitate encoding into long-term memory. All subjects were successful at this task. The 10 block letters (C, F, H, L, U, G, J, O, P, and S) previously used by Dror and Kosslyn (1994) were used for this task. The letters C, F, H, L, and U were classified as simple because each of these letters is composed of three or fewer segments. The letters G, J, O, P, and S were classified as complex because each includes four or more segments. The letters $\mathrm{O}$ and $\mathrm{L}$ were reserved for practice trials, leaving eight letters available for test trials.

An exclamation point first appeared on the screen to signal the start of each trial. When ready, the subjects pressed the space bar, after which a blank screen was presented for $500 \mathrm{msec}$. Next, a lowercase script version of one of the letters (e.g., ८) appeared for

A

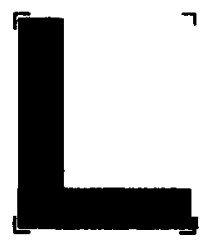

$\ell$

$\Gamma$

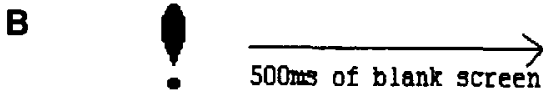

(space bar press)

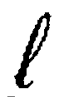

500 rus $\overrightarrow{500 \mathrm{~ns} \text { of blank screen }}$

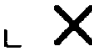

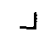

(yes/no response)

Figure 1. Examples of a stimulus presented during the learning stage (A) and a trial sequence in the image generation task (B). 
$500 \mathrm{msec}$, followed by a 500 -msec blank screen. Next, a set of four brackets forming a $2.6 \times 3.2 \mathrm{~cm}$ rectangular frame appeared with an $X$ mark, measuring $0.6 \times 0.6 \mathrm{~cm}$, appearing inside the frame. The location of the $X$ within the frame varied over each of 64 trials The subjects then decided whether or not the uppercase block letter that corresponded to the script letter presented on the computer screen would have covered the $X$ mark if the uppercase letter were to have appeared in the brackets. Of the 64 trials, 32 were simple letters ( 8 presentations each of $\mathrm{C}, \mathrm{F}, \mathrm{H}$, and $\mathrm{U}$ ) and 32 were complex letters $(G, J, S$, and $P)$. Each of the eight letters was presented four times with a corresponding $X$ mark in a position that would have been covered by the letter and four times with a corresponding $X$ mark in a position that would not have been covered by the letter.

\section{Results}

A $2 \times 2$ (sex $\times$ letter complexity) ANOVA was conducted, with RT and accuracy as the dependent variables, in order to test the hypothesis that females would outperform males in the image generation task. Results showed a main effect for sex of subject $[F(1,47)=6.05$, $\left.M S_{\mathrm{e}}=2,757,608, p=.018, d=.67\right]$, with RT for males $(M=1,512.00 \mathrm{msec}, S D=738.00)$ significantly faster than RT for females $(M=2,095.00 \mathrm{msec}, S D=961.00)$. There was also a significant main effect of complexity $\left[F(1,47)=49.69, M S_{\mathrm{e}}=264,823, p<.001\right]$. The sex of subject $X$ complexity interaction did not achieve statistical significance $[F(1,47)=0.34, p>.05]$. The increasing RTs as a function of letter complexity served as a manipulation check, suggesting that the subjects were performing the task as hypothesized. These results are shown in Table 1 (means are broken down by condition for males and females). The accuracy rates for females and males in both simple and complex letter conditions were not statistically different $[F(1,47)=0.76, p>.05]$. There were no statistically significant interactions with sex of subject in any of the analyses of accuracy data.

\section{Task 2 \\ Image Maintenance}

\begin{abstract}
Method
In the image maintenance task, the subjects made spatial decisions about a geometric pattern that was unrelated to language. The geometric patterns were not memorized before the test trials began because the task was designed to assess the maintenance of a visual image in working memory rather than retrieval from long-term memory. Each trial began with a $500-\mathrm{msec}$ presentation of an exclamation mark, followed by a blank screen of $500-\mathrm{msec}$ duration. One of the stimulus shapes was then presented on the screen. The subjects indicated that they memorized the pattern by pressing the space bar, which caused the pattern to disappear. The screen went blank for the next $2.500 \mathrm{msec}$; the subjects were required to retain an image of the pattern during this interval. Following this, an $X$ mark appeared
\end{abstract}

within a set of brackets. The subjects were asked to decide whether the stimulus shape would have covered the bracketed $X$ mark by pressing the appropriate key.

Stimuli were 24 different shapes, 8 in each of three levels of complexity. These stimuli consisted of shapes with one, two, or three vertical or horizontal bars with a constant width of $0.6 \mathrm{~cm}$ (see Figure 2). Forty-eight trials were presented. Twelve practice trials were presented before the test trials began, with four patterns at each of the three levels of complexity. Half of the patterns in each level were followed by an $X$ mark that would have been covered by the pattern, and half of the patterns were followed by an $X$ mark that would not have been covered by the pattern.

\section{Results}

RT and accuracy data for the image maintenance task were analyzed with a $2 \times 3$ (sex $\times$ number of pattern segments) ANOVA. As predicted, the results indicated a main effect for sex of subject $\left[F(1,47)=8.13, M S_{\mathrm{e}}=\right.$ $1,117,030, p=.006, d=.77$, with males showing a significantly shorter RT $(M=1,251.61 \mathrm{msec}, S D=356.49)$ than did females $(M=1,606.79, S D=495.24)$. Results also showed a main effect of pattern complexity $[F(2,92)=$ $\left.47.36, M S_{\mathrm{e}}=112,246, p<.001\right]$. The sex of subject $\times$ complexity interaction did not achieve statistical significance $[F(2,92)=0.86, p>.05]$. The increasing RTs as a function of pattern complexity served as a manipulation check, verifying that the subjects were performing the task as hypothesized. Table 2 displays the means for each condition. The accuracy rates for males were not significantly different from those for females $[F(2,92)=$ $0.37, p>.05]$.

\section{Task 3 \\ Image Scanning}

\section{Method}

In this task, the subjects were asked to view a $4.2 \times 4.2 \mathrm{~cm}$ frame, with each side composed of six $0.7 \times 0.7 \mathrm{~cm}$ squares, until they could readily visualize it from memory. Examples of these stimuli are shown in the middle portion of Figure 2. One square on each of three sides of the frame was black, and the rest of the squares were white. The location of the blackened squares along each side was varied. When ready, the subjects pressed the space bar, and a $0.4-$ $\mathrm{cm}$ arrow appeared for $50 \mathrm{msec}$ inside the frame in one of eight different orientations, ranging from the upright position of $0^{\circ}$ to $315^{\circ}$ and varying in $45^{\circ}$ increments. The arrow pointed to a target cell (either a black square or a white square) and was positioned at one of three distances from the target cell: adjacent, $1.2 \mathrm{~cm}$ away, or $2.1 \mathrm{~cm}$ away. Half of the trials at each distance presented arrows that pointed to a black target cell, and half the trials presented arrows that did not. Of the 60 test trials, 20 represented the arrow at each distance from the target cell. After the arrow had been displayed for $50 \mathrm{msec}$, both the arrow and the frame disappeared.

Table 1

Mean Reaction Time and Standard Deviations (in Milliseconds) and Accuracy Rate by Sex of Subject and Condition for the Image Generation Task

\begin{tabular}{|c|c|c|c|c|c|c|}
\hline \multirow{3}{*}{$\begin{array}{c}\text { Letter } \\
\text { Complexity }\end{array}$} & \multicolumn{3}{|c|}{ Females } & \multicolumn{3}{|c|}{ Males } \\
\hline & \multicolumn{2}{|c|}{$\mathrm{RT}$} & \multirow[b]{2}{*}{ Accuracy } & \multicolumn{2}{|c|}{ RT } & \multirow[b]{2}{*}{ Accuracy } \\
\hline & $M$ & $S D$ & & $M$ & $S D$ & \\
\hline Simple & $1,815.78$ & 824.94 & .93 & $1,274.93$ & 564.07 & .90 \\
\hline Complex & $2,376.89$ & $1,098.93$ & .80 & $1,750.44$ & 912.03 & .80 \\
\hline
\end{tabular}


A

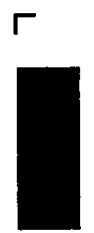

L.
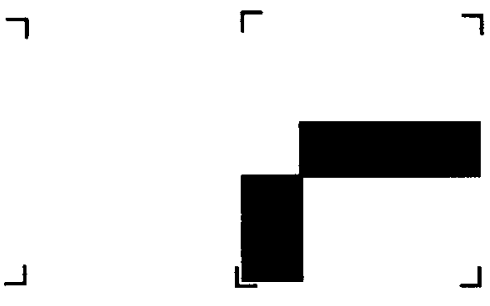

$\Gamma$

B

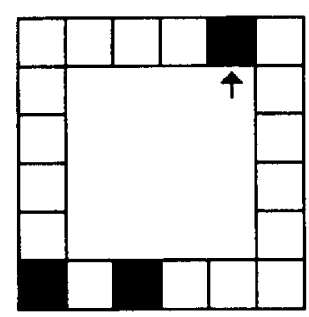

7

(1)

$\neg$

L
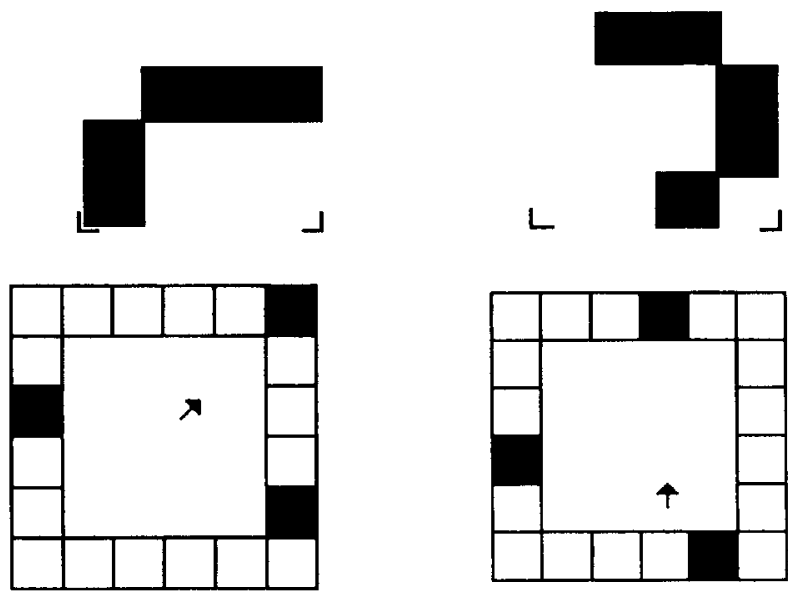

C
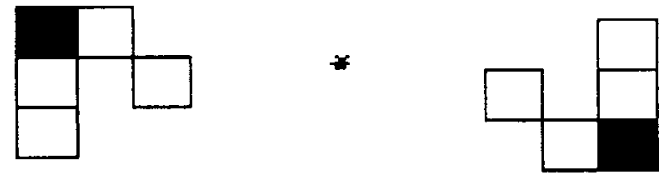

Figure 2. Examples of stimuli used for the image maintenance task (A), image scanning task (B), and image rotation task (C).

Thus, both the position of the arrow and the location of the blackened square had to be maintained in working memory while the subject scanned the image to determine whether the arrow pointed at the blackened square. Twelve practice trials were presented before test trials began, with 2 displaying arrows at each of the three distances that pointed to a black square, and 2 at each distance that did not.

\section{Results}

RT and accuracy data for the image scanning task were analyzed with a $2 \times 3(\operatorname{sex} \times$ arrow distance $)$ ANOVA.
The results indicated a main effect for sex of subject $\left[F(1,47)=5.37, M S_{\mathrm{e}}=265,609, p=.025, d=.63\right]$, with males showing shorter RTs $(M=850.11, S D=$ $227.59)$ than females $(M=989.46, S D=190.83)$. A main effect of arrow distance was also found $[F(2,94)=11.30$, $\left.M S_{\mathrm{e}}=26,551, p<.001\right]$. The sex of subject $\times$ arrow distance interaction did not achieve statistical significance $[F(2,94)=0.84, p>.05]$. Mean RTs for each condition are presented in Table 3 . The increasing RT as a function of arrow distance served as a manipulation check, show-

Table 2

Mean Reaction Time and Standard Deviations (in Milliseconds) and Accuracy Rate by Sex of Subject and Condition for the Image Maintenance Task

\begin{tabular}{lccccccc}
\hline & \multicolumn{3}{c}{ Females } & & \multicolumn{3}{c}{ Males } \\
\cline { 2 - 3 } \cline { 6 - 7 } \multicolumn{1}{c}{ Pattern } & \multicolumn{2}{c}{ RT } & & & \multicolumn{2}{c}{ RT } & \\
\cline { 2 - 3 } \cline { 6 - 7 } Complexity & $M$ & $S D$ & Accuracy & $M$ & $S D$ & Accuracy \\
\hline One segment & $1,316.33$ & 388.95 & .97 & & $1,026.49$ & 253.24 & .97 \\
Two segments & $1,663.51$ & 592.02 & .87 & & $1,303.96$ & 381.28 & .89 \\
Three segments & $1,840.54$ & 593.26 & .88 & $1,424.39$ & 527.53 & .89 \\
\hline
\end{tabular}

Table 3

Mean Reaction Time and Standard Deviations (in Milliseconds) and Accuracy Rate by Condition and Sex of Subject for the Image Scanning Task

\begin{tabular}{|c|c|c|c|c|c|c|}
\hline \multirow{3}{*}{$\begin{array}{c}\text { Arrow } \\
\text { Distance }\end{array}$} & \multicolumn{3}{|c|}{ Females } & \multicolumn{3}{|c|}{ Males } \\
\hline & \multicolumn{2}{|c|}{ RT } & \multirow[b]{2}{*}{ Accuracy } & \multicolumn{2}{|c|}{ RT } & \multirow[b]{2}{*}{ Accuracy } \\
\hline & $M$ & $S D$ & & $M$ & $S D$ & \\
\hline Adjacent & 919.36 & 172.23 & .96 & 812.04 & 201.03 & .97 \\
\hline $1.2 \mathrm{~cm}$ & 988.96 & 193.04 & .88 & 845.70 & 247.87 & .90 \\
\hline $2.1 \mathrm{~cm}$ & $1,060.05$ & 248.93 & .89 & 892.58 & 294.44 & .89 \\
\hline
\end{tabular}


ing that the subjects were performing the task as hypothesized. The accuracy rates for females and males were not statistically different $[F(2,94)=0.05, p>.05]$.

\section{Task 4}

\section{Image Rotation}

\section{Method}

The image rotation task required the subjects to decide whether or not a pair of two-dimensional figures was identical (see the lower portion of Figure 2). The figure on the left was the reference figure, and the figure on the right was either identical to the reference or mirror-reversed. The position of the figure on the right was varied in four different levels of orientation: $0^{\circ}, 90^{\circ}, 135^{\circ}$, or $180^{\circ}$. The figures were composed of two or three bars, with a width of $0.6 \mathrm{~cm}$ and a maximum overall size of $2.6 \times 3.2 \mathrm{~cm}$. A black square was filled in at the top of each figure to assist the subjects in comparisons of the pairs. A total of 64 test trials was presented, with 16 in each of the four levels of rotation. Half the figures (8) were identical after rotation, and half were mirror-reversed. Within each set of 8 trials, 4 of the figures were composed of two bars, and 4 were composed of three bars. Test trials began with an exclamation point appearing on the computer screen, as a signal to the subjects to get ready for each new trial. When ready, the subjects pressed the space bar, and a blank screen appeared for $500 \mathrm{msec}$. Next, a pair of figures was presented, and the subjects indicated that the figure on the right was identical by pressing one key or was mirror-reversed by pressing another key. Sixteen practice trials were presented before test trials, with 4 trials representing each condition.

\section{Results}

In a test of the hypothesis that males would outperform females in the mental rotation task, a $2 \times 2 \times 4$ (sex $\times$ number of figure segments $\times$ degree of rotation) ANOVA was computed, with RT and accuracy as the dependent variables. As predicted, results indicated a main effect for sex of subject $\left[F(1,47)=7.09, M S_{\mathrm{e}}=2,490,697\right.$, $p=.011, d=.73$ ], with males showing significantly shorter RTs $(M=2,177.81, S D=819.70)$ than females $(M=3,035.59, S D=1,348.62)$. A main effect was found for number of pattern segments $\left[F(1,47)=25.89, M S_{\mathrm{e}}=\right.$ $351,889, p<.001]$. A main effect of degree of rotation was also found $[F(3,138)=71.11, p<.001]$. The only statistically significant interaction was sex of subject $\times$ degree of rotation $[F(3,138)=5.09, p<.01]$. A Scheffé post hoc test revealed that the interaction occurred at $180^{\circ}$, where female RTs were significantly longer than male RTs (relative to their RTs at other orientations). The mean RTs for each degree of rotation (collapsed across pattern complex- ity) are shown in Table 4 . The accuracy rates for females were not significantly different from males for any of the $4^{\circ}$ of rotation $[F(3,138)=0.11, p>.05]$.

\section{DISCUSSION}

In an attempt to identify the cognitive processes that underlie female and male performance on visuospatial tasks, we used four laboratory tasks, each representing different component processes in visuospatial working memory. The finding that males performed all of these tasks at all levels of complexity more rapidly than females leaves us with the undifferentiated conclusion that males are more proficient, in general, at these tasks. The uniform finding across all four tasks is surprising given that these tasks have been used by Dror and his colleagues (Dror \& Kosslyn, 1994; Dror et al., 1993) to distinguish those components that decline with age from those that do not show an age-related decline and to identify those visuospatial processing components that pilots perform particularly well when compared with a matched sample of nonpilots. Dror's earlier findings led us to predict that the component processes involved in these tasks would also show a differential pattern of sex differences. The corresponding finding that males and females did not differ in accuracy on any of the tasks (at any of the various levels of complexity) also suggests that these results are not attributable to speed-accuracy tradeoffs, although it is possible that the generally high-accuracy results represent a ceiling effect and that sex differences in accuracy might occur with tasks that produce higher error rates.

In the present experiment, the image generation task required subjects to retrieve the shape of an uppercase (block) letter from long-term memory, mentally place it on a grid, and then use the retrieved or reconstructed image to decide whether a particular block on the grid would be covered by the letter. It is generally established that females excel on tasks that require retrieval from long-term memory (Stumpf \& Jackson, 1994) and that females are particularly adept when retrieving verbal material (Halpern, 1997). Although this task requires retrieval from long-term memory as a critical component process, the image generation task used here focused on the shape of letters, their imagined placement in space, and then the use of visuospatial working memory to make spatial decisions. In interpreting the results of the present

Table 4

Mean Reaction Time and Standard Deviations (in Milliseconds) and Accuracy Rate by Sex of Subject and Condition for the Image Rotation Task

\begin{tabular}{|c|c|c|c|c|c|c|}
\hline \multirow{3}{*}{$\begin{array}{c}\text { Degree of } \\
\text { Rotation }\end{array}$} & \multicolumn{3}{|c|}{ Females } & \multicolumn{3}{|c|}{ Males } \\
\hline & \multicolumn{2}{|c|}{ RT } & \multirow[b]{2}{*}{ Accuracy } & \multicolumn{2}{|c|}{ RT } & \multirow[b]{2}{*}{ Accuracy } \\
\hline & $M$ & $S D$ & & $M$ & $S D$ & \\
\hline 0 & $2,159.75$ & $1,328.48$ & .96 & $1,626.26$ & 736.03 & .92 \\
\hline 90 & $3,055.57$ & $1,317.20$ & .89 & $2,282.87$ & 841.84 & .86 \\
\hline 135 & $2,982.62$ & $1,086.44$ & .93 & $2,239.18$ & 832.44 & .89 \\
\hline 180 & $3,806.57$ & $1,670.43$ & .87 & $2,559.62$ & 997.13 & .89 \\
\hline
\end{tabular}


study, we now recognize that retrieval from long-term memory played a minor part in the execution of this task, because it was not included in the RTs that were collected, and the letters were not used in their usual natural-language context in this task. Thus, it seems that all four tasks were primarily assessing visuospatial working memory.

In view of the findings of the present study, it appears that females show a generalized slower RT on tasks that operate in visuospatial working memory, and these differences are unlikely to be attributed to any single processing component. Of note is the finding that females were particularly slow at the rotation task when the comparison figure was rotated at $180^{\circ}$. When figures are inverted, an effective strategy is to "flip" the comparison instead of rotating it to the upright. It is possible that fewer females utilized this spatial strategy and thus had a particularly long RT at this orientation. Visuospatial working memory is critical in many cognitive tasks that require subjects to generate a visual image and then maintain the information in that image while simultaneously transforming it in some way. Previous research has shown that, in general, males are better than females on spatiotemporal tasks - tasks that require judgments about and responses to dynamic (i.e., moving) visual displays. There are several different tasks that involve information that is moving, such as having subjects press a key when a target is coincident with a stationary line (Smith \& McPhee, 1987) and making "time of arrival" judgments about a moving object (Schiff \& Oldak, 1990). Despite differences among these tasks, they all rely on visuospatial working memory and the ability to infer change and movement while also storing visuospatial information.

The finding that the longer processing time did not "pay off" in greater accuracy for the females calls into question the interpretation that sex differences in visuospatial tasks are due to a greater concern with accuracy on the part of females (e.g., Goldstein, Haldane, \& Mitchell, 1990). Recent work by Masters (1998) is in accord with the present findings, in that she found no change in the size of the male advantage on mental rotation tasks in timed and untimed testing conditions. The present results also have implications for developers of academic selection tests, such as the Scholastic Achievement Test and Graduate Record Examination. Many questions on these tests require the generation, maintenance, and transformation of visuospatial configurations, although test takers usually can use paper and pencil to reduce the load on working memory. On average, males score higher than females on these high-stakes tests (Willingham \& Cole, 1997). These are speeded tests, which means that test takers who answer questions quickly are at an advantage compared with those who respond more slowly. Thus, speededness, or the number of problems that most people are expected to answer in the time allotted, is likely to be an important factor that has a negative differential impact on the performance of females on these tests.

Other lines of evidence support the conclusion that males, in general, are more proficient in their use of visuospatial imagery. Males are more likely to use imagery when solving problems, especially problems that involve moving objects (Richardson, 1991). Perhaps the male advantage on spatiotemporal tasks can be partially explained by the use of visual imagery in these tasks. We also note that the size of the sex difference on many tests of visuospatial processing can be reduced with training (e.g., Vasta \& Gaze, 1996). Converging support for these conclusions comes from a study of gifted students who were either in the top $20 \%$ in spatial ability or the top $20 \%$ in verbal ability. For both females and males, twice the number of students who were majoring in the physical sciences were in the high-spatial-ability group (Humphreys, Lubinski, \& Yao, 1993). Given the importance of visuospatial ability success in the physical sciences and many other professions (e.g., dentistry, carpentry, fashion design), Humphreys et al. argued for the addition of visuospatial tests to the math and verbal test batteries that are used for admission to colleges and graduate schools. We believe that a better understanding of individual differences in visuospatial working memory will provide new directions for future research and the development of human talent in this area.

\section{REFERENCES}

BADDELEY, A. D. (1990). Human memory: Theory and practice. Needham Heights, MA: Allyn \& Bacon.

BADDELEY, A. D. (1992). Working memory. Science, 255, 556-559.

Birendaum, M., Kelly, A. E., \& Levi-Keren, M. (1994). Stimulus features and sex differences in mental rotation test performance. Intelligence, 19, 51-64.

COHEN, J., \& COHEN, P. (1983). Applied multiple regression/correlation analysis for behavioral sciences. Hillsdale, NJ: Erlbaum.

Collins, D. W., \& Kimura, D. (1997). A large sex difference on a twodimensional mental rotation task. Behavioral Neuroscience, 111, 845-849.

Clarkson-Smith, L., \& Halpern, D. F. (1983). Can age-related deficits in spatial memory be attenuated through the use of verbal coding? Experimental Aging Research, 9, 179-184.

Dror, I., \&, Kosslyn, S. M. (1994). Mental imagery and aging. Psychology of Aging, 9, 90-102.

Dror, I. E., KosSLYN, S. M., \& WAAG, W. L. (1993). Visuospatial abilities of pilots. Journal of Applied Psychology, 78, 763.773.

Eals, M., \& Silverman, I. (1994). The hunter-gatherer theory of spatial sex differences: Proximate factors mediating the female advantage in recall of object arrays. Ethology \& Sociobiology, 15, 95105.

Galea, L. A. M., \& Kimura, D. (1993). Sex differences in route-learning. Personality \& Individual Differences, 14, 53-65.

Goldstein, D.. Haldane, D., \& Mitchell. C. (1990). Sex differences in visual-spatial ability: The role of performance factors. Memory \& Cognition, 18, 546-550.

HALPERN, D. F. (1997). Sex differences in intelligence: Implications for education. American Psychologist, 52, 1091-1102.

HALPERN, D. F. (in press). Sex differences in cognitive abilities ( $3 \mathrm{rd}$ ed.). Mahwah, NJ: Erlbaum.

Halpern, D. F., \& Crothers, M. (1997). The sex of cognition. In L. Ellis (Ed.), Sexual orientation: Toward biological understanding (pp. 181-197). Westport, CT: Praeger.

HALPERN, D. F. \& WRIGHT, T. (1996). A process-oriented model of cognitive sex differences. Learning \& Individual Differences, 8, 39-56.

HerlitZ, A., NilsSON, L.-G., \& BÄCKMAN, L. (1997). Gender differences in episodic memory. Memory \& Cognition, 25, 801-811.

Hertzog, C., Vernon, M. C., \& Rypma, B. (1993). Age differences in mental rotation task performance: The influence of speed/accuracy tradeoffs. Journal of Gerontology, 48, 150-156.

Hil.l, R. D., Grut, M., Wahlin, A., Herlitz, A., Winblad, B., \& 
BäCKMAN, L. (1995). Predicting memory performance in optimally healthy very old adults. Journal of Mental Health \& Aging, 1, 55-65.

HUMPHREYS, L. G., LUBINSKI, D., \& YAO, G. (1993). Utility of predicting group membership and the role of spatial visualization in becoming an engineer, physical scientist, or artist. Journal of Applied Psychology, 78, 250-261.

James, T. W. \& Kimura, D. (1997). Sex differences in remembering the locations of objects in an array: Location-shifts versus locationexchanges. Evolution \& Human Behavior, 18, 155-163.

Linn, M. A., \& Petersen, A. C. (1985). Emergence and characterization of sex differences in spatial ability: A meta-analysis. Child Development, 56, 1479-1498.

MASTERS, M. S. (1998). The gender difference on the Mental Rotations test is not due to performance factors. Memory \& Cognition, 26, 444-448.

Masters, M. S., \& SANDERS, B. (1993). Is the gender difference in mental rotation disappearing? Behavior Genetics, 23, 337-341.

OKaGaKi, L., \& Frensch, P. A. (1994). Effects of video game playing on measures of spatial performance: Gender effects in late adolescence. Journal of Applied Developmental Psvchology, 15, 33-58.

RicharDSON, J. T. E. (1991). Gender differences in imagery, cognition, and memory. In R. H. Logie \& M. Denis (Eds.), Mental images in human cognition (pp. 271-303). London: Elsevier.

Schaie, K. W., \& Willis, S. L. (1993). Age difference patterns of psychometric intelligence in adulthood: Generalizability within and across ability domains. Psychology \& Aging, 8, 44-55.

SCHIFF, W., \& Oldak, R. (1990). Accuracy of judging time to arrival: Effects of modality, trajectory, and gender. Journal of Experimental Psychologv: Human Perception \& Performance, 16, 303-316.

SCHNEIDER, W. (1989). Enhancing a standard experimental delivery system (MEL) for advanced psychological experimentation. Behavior Research Methods, Instruments, \& Computers, 21, 240-244.
Silverman, I., \& Eals, M. (1992). Sex differences in spatial abilities: Evolutionary theory and data. In J. Barkow, L. Cosmides, \& J. Tooby (Eds.), The adapted mind: Evolutionary psychology and the generation of culture (pp. 487-503). Oxford: Oxford University Press

SMith, G. A., \& MCPhee, K. A. (1987). Performance of a coincidence timing task correlates with intelligence. Intelligence, 11, 161-167.

StUMPF, H., \& JaCKSON, D. N. (1994). Gender-related differences in cognitive abilities: Evidence from a medical school admissions testing program. Personality \& Individual Differences, 17, 335-344.

VASTA, R., \& GAZE, C. E. (1996). Can spatial training erase the gender differences on the water-level task? Psychology of Women Quarterly, 20, 549-567.

VOYer, D., Voyer, S., \& BRyden, M. P. (1995). Magnitude of sex differences in spatial abilities: A meta-analysis and consideration of critical variables. Psychological Bulletin, 117, 250-270.

Willingham, W. W., \& Cole, N. S. (1997). Gender and fair assessment. Hillsdale, $\mathrm{NJ}$ : Erlbaum.

\section{NOTE}

1. Some authors prefer to use the term sex to refer to variables that are primarily biological in origin and gender to refer to variables that are primarily social in origin. On the basis of the belief that it is often difficult to label a variable as primarily biological or social, the term sex is used in this paper without regard to the purported origin or main cause for an effect.

(Manuscript received January 20, 1998; revision accepted for publication October 27, 1998.) 